\title{
A busca de um novo modelo de gestão para a ciência, tecnologia e inovação na política do MCT (1995-2002)*
}

\section{Alexandre Veronese**}

SuMÁRIO: 1. Introdução; 2. O setor de C\&T brasileiro e seus impasses; 3. Reforma do Estado e reforma administrativa; 4. Em busca de novos formatos institucionais; 5. Conclusão: burocracia e burocratização.

S U M MARY : 1. Introduction; 2. The science and technology sector in Brazil and its deadlocks; 3. State reform and administrative reform; 4. In search of new institutional models; 5 . Conclusion: bureaucracy and bureaucratization.

P ALAVRAS-CHAVE: reforma do Estado; reforma administrativa de 1995; gestão em ciência e tecnologia; política científica e tecnológica.

KEY WORDS: state reform; 1995 administrative reform; science and technology management; science and technology policies.

Este artigo mostra como a agenda da reforma administrativa de 1995 foi incorporada aos objetivos traçados pela política científica do Ministério da Ciência e Tecnologia (MCT) nos dois governos passados (1995-2002). A área de ciência e tecnologia, no Brasil e no mundo, tem passado por dramáticas mudanças. Um desses tipos de mudança se refere às pressões para o estabelecimento de uma nova forma de gerir o

* Artigo recebido em jan. 2004 e aceito em ago. 2005. Uma versão preliminar foi apresentada no V Simpósio de Filosofia e Ciência, realizado na Universidade Estadual Paulista Júlio de Mesquita (Unesp, Marília), no XI Congresso Brasileiro de Sociologia, realizado na Unicamp, e no seminário A Produção Científica em Centros de Pesquisa, na Fundação Casa de Rui Barbosa, todos em 2003.

** Analista em ciência e tecnologia no Ibict e pesquisador assistente do Instituto de Pesquisas e Estudos Jurídicos do Centro Universitário da Cidade (Rio de Janeiro). Doutorando em sociologia pelo Iuperj, mestre em sociologia e direito pela UFF. Endereço: MCT/Ibict - Coordenação de Ensino e Pesquisa. Rua Lauro Müller, 455, sala 505 — Botafogo — CEP 22290-160, Rio de Janeiro, RJ, Brasil. E-mail: veronese@uninet.com.br. 
processo científico e tecnológico. Este artigo começa com uma análise do estágio de desenvolvimento do setor de ciência e tecnologia brasileiro e seus impasses. A seguir, faz uma exposição sobre a reforma do Estado nas décadas de 1980 e 1990 e a reforma administrativa de 1995. Depois, trata da agenda da política de C\&T, com ênfase na busca de novos formatos institucionais. Conclui que, ao mesmo tempo que o setor está burocratizado, a sociedade brasileira também segue o percurso de sua burocratização. E, assim, mostra que, por esse processo de burocratização da sociedade não ter sido identificado no traçado das políticas setoriais do MCT, o ministério apostou numa proposta de desregulamentação que, provavelmente, não dará conta da necessidade de novos formatos na política de gestão para as suas unidades de pesquisa.

A new management model for science, technology and innovation in the Department of Science and Technology policy (1995-2002)

This article shows how the agenda of the 1995 administrative reform was incorporated into the policy goals of the Department of Science and Technology during its two last terms (1995-2002). The area of science and technology (S\&T) in Brazil and abroad has gone through dramatic changes. One of these changes refers to the pressures for a new form of managing the S\&T process. This article begins by analyzing the stage of development of S\&T in Brazil and its roadblocks. It then discusses the State reform of the 1980's and 90's and the 1995 administrative reform, as well as the S\&T policy agenda, emphasizing the search for new institutional models. It concludes that both the sector and the Brazilian society are highly bureaucratic. And, because this process of bureaucratization was not identified when the Department of Science and Technology outlined its sectorial policies, the department invested in a deregulation proposal that probably will not respond to the need for new management models in its research units.

\section{Introdução}

Este artigo demonstra a absorção da agenda da reforma administrativa de 1995 entre os objetivos traçados pela política científica do Ministério da Ciência e Tecnologia (MCT) nos dois governos passados (1995-2002). A próxima seção analisa o desenvolvimento do setor de ciência e tecnologia (C\&T) e seus impasses. Na seção seguinte, faremos uma breve exposição sobre a reforma do Estado das décadas de 1980 e 1990 e a reforma administrativa de 1995. A seguir, trataremos da agenda da política de C\&T, com ênfase na sua busca por novos formatos institucionais. Por fim, concluiremos que, se o setor é burocratizado, a sociedade brasileira também o é. E, desse modo, mostraremos que, pelo fato de este processo de burocratização da sociedade não ter sido identificado no traçado das políticas setoriais do MCT, apostouse numa proposta de desregulamentação que, provavelmente, não dará conta da ne- 
cessidade de novos formatos institucionais para as unidades de pesquisa científica e tecnológica ligadas àquele ministério.

Existem, hoje, no sistema federal 19 unidades de pesquisa vinculadas diretamente ao MCT. ${ }^{1}$ No Rio de Janeiro, Centro Brasileiro de Pesquisas Físicas (CBPF), Observatório Nacional (ON), Museu de Astronomia e Ciências Afins (Mast), Centro de Tecnologia Mineral (Cetem), Instituto de Matemática Pura e Aplicada (Impa) e Instituto Nacional de Tecnologia (INT); em Petrópolis, Laboratório Nacional de Computação Científica (LNCC); em Campinas, Laboratório Nacional de Luz Síncrotron (LNLS) e Centro de Pesquisas Renato Archer (Cenpra); ${ }^{2}$ em São José dos Campos, Instituto Nacional de Pesquisas Espaciais (Inpe); em Itajubá, Laboratório Nacional de Astrofísica (LNA); em Brasília, Instituto Brasileiro de Informação em Ciência e Tecnologia (Ibict) e Centro de Gestão e Estudos Estratégicos (CCEE); ${ }^{3}$ em Belém, Museu Paraense Emilio Goeldi (MPEG); em Manaus, Instituto Nacional de Pesquisas da Amazônia (Inpa); em Tefé, na Amazônia, o Instituto de Desenvolvimento Sustentável Mamirauá (IDSM); e nas cercanias da Usina Hidroelétrica de Xingó, na região Nordeste, o Programa Xingó. Também tem caráter de unidade de pesquisa a Rede Nacional de Pesquisas (RNP). ${ }^{4}$ A Comissão Nacional de Energia Nuclear (CNEN), suas empresas — organizadas na holding Indústrias Nucleares do Brasil (INB) - e as suas cinco unidades de pesquisas Centro de Desenvolvimento de Tecnologia Nuclear (CDTN), Centro Regional de Ciências Nucleares (CRCN), Instituto de Engenharia Nuclear (IEN), Instituto de Pesquisas Nucleares (Ipen) e Instituto de Radioproteção e Dosimetria (IRD) — também foram vinculadas ao MCT. Igualmente, a Agência Espacial Brasileira (AEB) tem estatuto de unidade de pesquisa. São, portanto, ao todo, 24 unidades.

Além destas, temos diversos institutos e empresas importantes no setor de C\&T que não são vinculados ao MCT. Entre outros, podemos citar a Fundação Instituto Oswaldo Cruz (Fiocruz), do Ministério da Saúde. Também, o Instituto de Pesquisas Econômicas Aplicadas (Ipea) e a Fundação Instituto Brasileiro de Geografia e Estatística (IBGE), ambos ligados ao Ministério do Planejamento, Orçamento e Gestão. Ainda, a Empresa Brasileira de Pesquisa Agropecuária (Em-

\footnotetext{
${ }^{1}$ Houve um grande rearranjo no vínculo institucional das unidades de pesquisa, no início da gestão do ministro Ronaldo Mota Sardenberg, em 1999. As unidades do CNPq foram transferidas para o MCT. A Comissão Nacional de Energia Nuclear (CNEN) e suas unidades também foram alocadas junto ao MCT. ${ }^{2}$ Herdeiro da antiga Fundação Centro de Tecnologia para Informática (CTI). Parte dessa unidade está em Brasília, na Presidência da República, ocupando-se da infra-estrutura de chaves públicas (ICP-Brasil), que será a base do sistema de certificação digital. É o Instituto Nacional de Tecnologia da Informação (ITI).

${ }^{3}$ Esta organização social foi criada em 2001 e sucedeu o Centro de Estudos Estratégicos (CEE) do MCT.

${ }^{4}$ Foi criada uma organização social: a Associação Rede Nacional de Ensino e Pesquisa (RNP) para gerir o sistema de redes de dados científicos e tecnológicos, no Brasil.
} 
brapa), do Ministério da Agricultura. O Instituto Nacional de Metrologia, Normalização e Qualidade Industrial (Inmetro) e o Instituto Nacional de Propriedade Industrial (Inpi), vinculados ao Ministério do Desenvolvimento, Indústria e Comércio Exterior. A Fundação Joaquim Nabuco (Fundaj) e a Fundação Casa de Rui Barbosa, do Ministério da Cultura. Mais a Companhia de Pesquisas de Recursos Minerais (CPRM) e o Centro de Pesquisas e Desenvolvimento Leopoldo Miguez de Mello (Cenpes), este último vinculado à Petrobras, no Ministério de Minas e Energia. E, por fim, junto ao Ministério da Defesa, o Centro Técnico Aeroespacial (CTA) e o Instituto Militar de Engenharia (IME).

Também deve ser mencionada a consolidação parcial de uma ampla plataforma de universidades e instituições isoladas de educação superior (estatais e privadas). Este sistema de educação superior foi responsável pela formação de 2.085.120 graduados em 1998. Isto representou um aumento de mais de 50\% em relação aos 1.377 .286 formados em 1980, por exemplo (Castro, 1998:39). E foi também responsável pela formação de boa parte dos 18.374 mestres e dos 5.344 doutores diplomados no Brasil, em 2000 (Brasil, MCT, 2001:31).

O que pode ser depreendido, das informações antes mencionadas, é que as unidades de pesquisa do MCT respondem apenas por uma parte muito pequena da produção e dos dispêndios em ciência e tecnologia.

\section{O setor de C\&T brasileiro e seus impasses}

Ao longo do século XX o Brasil desenvolveu um amplo sistema de produção de C\&T (Schwartzman, 1995). A agenda do MCT, para o biênio 2001/02, foi tentar, partindo da plataforma instalada, expandir o nível de inovação tecnológica do setor produtivo nacional. Assim, conseguiria mudar o enfoque de atuação da C\&T para a produção de ciência, tecnologia e inovação (CT\&I). Para alcançar tal objetivo, o MCT vinha buscando induzir em maior escala e produzir diretamente em menor escala. Os dados não desmistificam o fato de que o país alcançou um bom patamar na produção científica internacional. Hoje o Brasil produz mais de 1\% dos artigos indexados publicados em periódicos internacionais.

Esse fato, da consolidação da produção científica, é comemorado por dirigentes de órgãos federais de fomento e por diversos respeitáveis pesquisadores (Neves, 2001; Velloso e Velho, 2001). Mas esses números podem ter uma leitura negativa também. No ano de 2001, foram comemorados os aniversários dos 50 anos da Fundação Coordenação de Aperfeiçoamento de Pessoal de Nível Superior (Capes) e do Conselho Nacional de Desenvolvimento Científico e Tecnológico (CNPq). Uma das conclusões possíveis é que após o transcurso de todo este tempo (e investimentos), o nosso país já poderia estar numa posição mais confortável na escala 
internacional dos países produtores de C\&T. Principalmente se compararmos a nossa posição na escala com o nosso PIB ou com o nosso grande contingente populacional e territorial (Schott, 1995).

Assim, se demos passos ao futuro, devemos acelerar ainda mais a corrida para garantir a institucionalização do setor. E, no entender do MCT, estes passos deviam estar dirigidos para a inovação tecnológica e para o desenvolvimento do parque produtivo nacional, como podia ser depreendido do Livro Verde (Brasil, MCT e ABC, 2001:115-116, grifos do autor). ${ }^{5}$

[H]á a percepção [mundial] de que o conhecimento é o elemento central de uma nova estrutura econômica que está surgindo, de que a aprendizagem é seu mais importante processo e de que a inovação é o principal veículo de transformação do conhecimento em valor [,que] permite aos países desenvolvidos e [a] um grupo de países em desenvolvimento adotem [adotar] iniciativas para colocar ciência, tecnologia e inovação no centro da agenda política e econômica (...). Apesar de sua recente intensificação, os esforços até agora realizados ainda não foram suficientes para que a geração do conhecimento e a inovação tecnológica entrassem em definitivo na agenda do país.

Desse modo, além de festejar, os dados induziam à conclusão de que existiam problemas que deviam ser resolvidos para que pudéssemos chegar no patamar ideal de produção em CT\&I. Uma das questões mais intrigantes dos estudos industriais é o porquê do baixo índice de inovação tecnológica nos processos produtivos nacionais. José Leite Lopes (1998:111), um dos decanos da física brasileira, professor emérito da UFRJ e pesquisador emérito do CBPF, considera que:

Nos países dominados a implantação de filiais das empresas multinacionais não implica de maneira alguma a criação de laboratórios de pesquisa nestas subsidiárias. (...) Fica claro, portanto, que as corporações multinacionais - e as economias que as dominam — não precisam dos serviços dos cientistas nacionais nem de universidades independentes nos países subdesenvolvidos em que se estabelecem.

\footnotetext{
${ }^{5}$ O Livro Verde (Brasil, MCT e ABC, 2001), produzido pelo MCT e pela Academia Brasileira de Ciências (ABC), é o resultado da síntese de diversos artigos e trabalhos solicitados pelo MCT ao longo de 2001. Ele serviu como texto básico para as diversas conferências regionais de CT\&I realizadas naquele ano. E, também, para a conferência final (nacional) em Brasília, também em 2001.
} 
A leitura de Leite Lopes é ponderada a partir de uma perspectiva nacional-desenvolvimentista que marcou a trajetória do setor estatal de C\&T. Desde os seus momentos de inicial desenvolvimento, na década de 1950, com a introdução da agenda nuclear ${ }^{6}$ (e a criação do CNPq e da Capes), até o período militar, nas décadas de 1960 e 1970, dominava o cenário político científico a perspectiva de construção do Brasil-potência. De fato, atualmente, experiências alvissareiras de fomento à inovação mostram que não basta culpar a burguesia nacional. Ao contrário, estudos ponderam que é possível que os setores industriais se engajem na agenda de incremento da inovação tecnológica do parque produtivo.

Entretanto, a questão não é tão simples, pois é necessário construir sinergias entre setores que se antagonizaram há muito. Experiências de parcerias entre o setor produtivo já existiram e existem no Brasil. Basta lembrar da atuação do setor produtivo estatal em conjunto com universidades e centros de pesquisa estatais. Um exemplo, sobre a condução destas relações nos anos 1970, pode ser visto na declaração de um diretor de uma das unidades de pesquisa do MCT, em 2001: ${ }^{7}$

\begin{abstract}
Nós nascemos numa época [a unidade, em 1980] em que as estatais [nos] estimulavam. O governo e as estatais contratavam a gente para desenvolver projetos de desenvolvimento tecnológico em empresas. (...) As negociações eram num estilo meio político. Você negociava grandes projetos. A gente negociava um projeto, por exemplo, da represa de Tucuruí. (...) Nós fomos contratados pela Eletronorte, durante três anos, para desenvolver um sistema [e para] adaptar um sistema existente nos EUA, passando para Tucuruí fazer essa análise. (...) Junto com o pessoal ligado à parte de liminologia e ecologia do Inpa da Amazônia. Na verdade, nós fomos subcontratados para fazer o modelo computacional pelo Inpa. Então eram grandes oportunidades que a gente negociava no nível da própria direção da empresa, direção da instituição e tudo isso. A gente negociava projetos e ficava envolvido durante vários anos. Então, zerou isso, [pois] não tinham [mais] fundos. Tem uma parte intermediária desses anos 1990 que não tinha mais isso. As empresas (nem a Petrobras!) não queriam fazer mais nada, porque tinham outras perspectivas.
\end{abstract}

Mas esta operação, tal como descrita pelo diretor, era uma operação intra-estatal. Era um acordo entre duas áreas do Estado. Contemporaneamente, podemos visualizar a

\footnotetext{
${ }^{6}$ Sobre a introdução da agenda nuclear no Brasil é referência obrigatória o livro de Andrade (1999), em especial o capítulo 3.

${ }^{7}$ Para a realização da dissertação de mestrado junto ao PPGSD-UFF foram realizadas 12 entrevistas com dirigentes do MCT e de financiadoras federais, das unidades de pesquisa e com servidores (pesquisadores e técnicos), além da participação e observação em diversas reuniões e atos públicos.
} 
existência, no imaginário dos atores sociais (pesquisadores, professores, dirigentes, políticos etc.), de uma dicotomia de interesses na chave público (ou, de fato, estatal) versus privado. Ela ocorre tanto no setor de educação superior (Nunes, 2002), quanto no setor de C\&T. É uma dicotomia que atrapalha a definição de objetivos interinstitucionais entre instituições de pesquisa/educacionais e empresas industriais. Com tal confusão, as instituições acabam não podendo se especializar. Por exemplo, as instituições de educação superior privadas poderiam desenvolver um papel complementar importante no sistema educacional e de C\&T. Entretanto, acabam reproduzindo um modelo importado das universidades estatais. As relações entre empresas privadas e centros de pesquisa estatais são um dos mais complexos nós do sistema. Essa dicotomia foi incrementada com o fim da doutrina do nacional-desenvolvimentismo e com a introdução de uma certa liberdade às instituições. Levou a um laissez-faire na política de C\&T. Neste “liberalismo de bancada”, os bons departamentos e laboratórios concentram recursos públicos e privados, sem controle ou planejamento por parte das reitorias. Em 2001, um dirigente de uma das financiadoras federais ${ }^{8}$ de pesquisa científica e tecnológica nos mencionou que:

\begin{abstract}
Embora seja um descontrole total por parte das reitorias, das administrações universitárias... (...) E por causa desse descontrole, você tem uma política de laissez faire. Você lá, no seu laboratório, Alexandre, faz o que você quiser... Essa é que é a verdade. Se você for o piloto das coisas, você alavanca dinheiro, bota gente lá dentro, consegue bolsas, equipamento, viagens... Você faz o diabo. Porque ela te permite, a universidade. Então, você tem um paradoxo nisso. Você tem um sistema absolutamente não planejado que gera externalidades importantes. (...) No fundo é um argumento quase liberal para a universidade. A universidade hoje vive um sistema, entre aspas, liberal. Façam o que quiserem... Deixa o mercado (entre aspas) das universidades, agir. E elas estão agindo e crescendo. O que não quer dizer que você não precise de planejamento. Você precisa de planejamento interno. O potencial é enorme! O que se faz, hoje, é um desperdício. Existe um desperdício. O laissez faire está gerando desperdício. E nós não podemos desperdiçar. Então, exige planejamento, sim. Os sistemas coordenados de inovação são sistemas onde os papéis são claros. Você sabe como cada um funciona e sabe articular o que cada um tem que fazer dentro do sistema.
\end{abstract}

Enquanto persistirem antagonismos desta monta entre os diversos atores, teremos problemas na construção de sinergias entre o setor produtivo e os produtores de

\footnotetext{
${ }^{8}$ Podemos considerar como financiadoras federais o CNPq, a Capes e a Financiadora de Estudos e Projetos (Finep).
} 
C\&T. Esta percepção é consoante com a compreensão de Luiz Carlos Bresser-Pereira (1996, 1998 e 2000) cujas idéias orientaram a construção do processo de reforma administrativa de 1995, em marcha durante os dois governos do presidente Fernando Henrique Cardoso (1995-2002). Mostraremos como houve um acoplamento desta percepção nos projetos setoriais do MCT de outrora.

\section{Reforma do Estado e reforma administrativa}

Um dos maiores problemas que assomam ao mencionarmos as reformas do Estado e as reformas administrativas é a confusão entre estes dois conceitos. Podemos dizer que uma reforma do Estado deve ser entendida como um momento específico e delimitado de grandes transformações no âmbito dos Estados nacionais. Ou que: "há momentos históricos — decorrentes de conjunturas específicas internacionais, nacionais ou pela conjugação de ambas - onde ocorrem rupturas de maior envergadura, que podem ser classificadas como de 'reforma do Estado’” (Diniz e Azevedo, 1997:12).

Já a definição conceitual do termo reforma administrativa, no caso da América Latina, confunde-se com a própria história das reformas, como menciona Peter Spink (1998:149) em artigo sobre o histórico dessas reformas. Em uma definição mais recente, a amplitude atribuída foi confundindo reforma administrativa com reforma do Estado:

Caiden, em seu estudo de 1991, apontou cerca de 16 áreas importantes de atribuições e atividades do Estado administrativo incluídas no significado de reforma administrativa: planejamento nacional, estabelecimento de programas, indicadores de desempenho; organização e estrutura da máquina governamental; Constituições, accountability, direito à informação; formulação de políticas públicas; execução de programas; elaboração de orçamento público e administração financeira; emprego público, práticas e condições; regulamentação, salvaguardas e práticas públicas; preservação e manutenção do capital público; serviços gerais - consistência, desempenho e padronização; empresas públicas - impacto na economia e retorno de investimento; práticas de gestão pública - O\&M [organização e métodos], desburocratização, eficiência e qualidade; ética pública - honestidade, profissionalismo, anticorrupção; participação do público - voluntarismo, atendimento de reclamações; [e] institucionalização da reforma — P\&D [pesquisa e desenvolvimento], treinamento, agências e escolas.

Temos claro que a reforma do Estado brasileiro não é somente um processo de reforma do aparelho do Estado. É um processo de reforma da sociedade e da economia brasileira (Baumann, 1999). Podemos dizer que seria, principalmente, um processo de reforma pela liberalização da sociedade e da economia. A agenda da re- 
forma administrativa de 1995 veio tentar colocar a administração pública no eixo das reformas orientadas para o mercado (market-biased). Mas não podemos entender, também, que por reforma administrativa se faça abranger toda e qualquer alteração em organogramas e fluxogramas funcionais (Spink, 1998; Bresser-Pereira, 1998). As reformas administrativas são multifacetadas e quando logram merecer esta nomenclatura é porque induziram sensível alteração no funcionamento e na lógica da administração pública.

Logo, podemos dizer que no período que compreendeu os dois governos do presidente Fernando Henrique Cardoso (1995-2002), assistimos a um efetivo processo de reforma administrativa. Esta reforma foi nomeada pelos seus propositores como uma reforma gerencial. Ou seja, ela emprestou sua orientação teórica ao chamado paradigma gerencial da administração pública (Bresser-Pereira, 1998; Ferlie et al., 1999). Apesar de sua amplitude e da existência de diversos detalhes na reforma administrativa de 1995, podemos dizer que, em geral, ela buscou orientar as organizações estatais de acordo com os parâmetros de mercado.

A melhor maneira de entender a reorientação gerencial é notar que a reforma administrativa de 1995 buscou reorganizar a atuação estatal em eixos diferentes. Ela procurava ordenar os setores públicos em setores estatais e não-estatais. E prosseguia com a continuidade na privatização de empresas estatais, combinada com a “publicização” de serviços sociais prestados pelo Estado. Esta “publicização” seria a formação de novos tipos de instituições: as organizações sociais (OS) e as organizações da sociedade civil de interesse público (Oscip). ${ }^{9}$

A reforma administrativa de 1995 teve maior ou menor sucesso em setores diferentes da administração pública, apesar de seu efetivo sucesso em termos de definição conceitual (Bresser-Pereira, 2000). Podemos dizer que na área federal de C\&T houve a absorção desta agenda, em especial nas questões institucionais e nos modelos de gestão, como será descrito a seguir.

\section{Em busca de novos formatos institucionais}

A melhor maneira de localizar a absorção da agenda da reforma administrativa de 1995 pela política traçada na gestão passada do MCT está alinhada aos desafios institucionais e de modelos de gestão para as unidades de pesquisa. E dentro desses desafios institucionais estava a busca por novos formatos institucionais para a produção científica e tecnológica. Como poderão as unidades de pesquisa e as uni-

\footnotetext{
${ }^{9}$ Não trataremos deste tipo de organização aqui. Importantes informações sobre esta qualificação para entidades da sociedade civil podem ser conferidas em Falcão e Cuenca (1999).
} 
versidades manterem contatos com as empresas e a sociedade, com o mínimo de turbulência e o máximo de produtividade? Entendemos que o problema subjacente à busca por novos formatos institucionais é a realização da equação da inovação tecnológica.

E, com este aspecto em detalhes, na verdade, vemos que o problema da inovação tecnológica não poderá ser simplesmente resolvido com a modificação apenas das unidades de pesquisa do MCT. Como ponderou Glaci Zacan, ex-presidente da Sociedade Brasileira para o Progresso da Ciência (SBPC), o maior problema institucional está localizado nas universidades. E não somente nas universidades estatais. A questão da reforma universitária e da autonomia universitária é diretamente influente em todos os setores da educação superior com conseqüências diretas para o setor produtivo.

Desde o início do governo do presidente Fernando Henrique Cardoso, em 1995, já haviam sido feitas tentativas de introduzir modificações no sistema das unidades de pesquisa do MCT. Foram duas propostas: a primeira, lançada pelo então presidente do CNPq, José Galizia Tundisi, era transferir todas as unidades de pesquisa do CNPq para o MCT. Não foi efetivada naquele momento, mas acabou sendo realizada em 1999/2000; a outra proposta era o projeto da criação das Fundações Nacionais de Pesquisa. Esta proposta, feita pelo então ministro da Ciência e Tecnologia, Israel Vargas, seria a reordenação das unidades de pesquisa do CNPq e do MCT em quatro grandes fundações formadas pela agregação de várias unidades. O quadro mostra como elas ficariam distribuídas.

\begin{tabular}{|ll|}
\hline \multicolumn{1}{|c|}{ Fundação } & \multicolumn{1}{c|}{ Unidades } \\
\hline Fundação Nacional de Pesquisa Equatorial & $\begin{array}{l}\text { Instituto Nacional de Pesquisas da Amazônia } \\
\text { (Inpa), Museu Paraense Emílio Goeldi (MPEG) e } \\
\text { Projeto Mamirauá (depois Instituto de } \\
\text { Desenvolvimento Sustentável Mamirauá). }\end{array}$ \\
Fundação Nacional de Pesquisa Espacial & $\begin{array}{l}\text { Instituto Nacional de Pesquisas Espaciais (Inpe) e o } \\
\text { seu Centro de Previsão do Tempo e Estudos do } \\
\text { Fundação Nacional de Pesquisa Científica }\end{array}$ \\
& $\begin{array}{l}\text { Centro Brasileiro de Pesquisas Físicas (CBPF), } \\
\text { Laboratório Nacional de Computação Científica } \\
\text { (LNCC), Observatório Nacional (ON), Instituto de } \\
\text { Matemática Pura e Aplicada (Impa) e Laboratório } \\
\text { Nacional de Luz Síncrotron (LNLS). }\end{array}$
\end{tabular}

RAP Rio de Janeiro 40(1):107-25, Jan./Fev. 2006 
Fundação Nacional de Pesquisa e Desenvolvimento Tecnológico
Fundação Centro de Tecnologia de Informática (CTI) (depois transformado no Instituto Nacional de Tecnologia para Informática, ITI e depois desmembrado em ITI e CenPRA) e Centro de Tecnologia Mineral (Cetem).

Note que estão ausentes o Instituto Nacional de Tecnologia (INT) e o Instituto Brasileiro de Informação em Ciência e Tecnologia (Ibict). Tanto o Museu de Astronomia e Ciências Afins (Mast), quanto o Laboratório Nacional de Astrofísica (LNA) ainda não haviam sido plenamente desmembrados do Observatório Nacional (ON). Já o Centro de Gestão e Estudos Estratégicos (CGEE), o Projeto Xingó e a Rede Nacional de Pesquisa (RNP) ou não existiam, ou não eram organizados como unidades de pesquisa. Também deve ser notado que não foi pensado, naquele momento, no papel da Comissão Nacional de Energia Nuclear, com suas empresas e unidades de pesquisa.

Nenhuma dessas duas propostas, a de agregação das unidades tanto no âmbito do MCT quanto no âmbito das fundações, foi efetivada. As atenções acabaram se voltando, naquele início do primeiro governo do presidente Fernando Henrique Cardoso (1995-98), para outras duas propostas. A primeira era a dos Laboratórios Associados ou o Programa Nacional de Centro de Excelência (Pronex). E a segunda era uma nova proposta de autonomia universitária, por parte do Ministério da Educação (MEC).

A primeira nova proposta, os Laboratórios Associados, era basicamente fomentar as associações entre vários grupos de pesquisa para a formação de projetos associados e de maior impacto. Acabou sendo conhecida, após reformulações, como Programa Nacional de Centros de Excelência (Pronex). Ela funcionou razoavelmente até o ano de 2000. A descontinuidade no repasse das verbas foi decisiva para sua diminuição em importância. ${ }^{10}$ A segunda proposta, de autonomia universitária, poderia ter tido um grande impacto no setor de C\&T. Após um grande período de disputas e pressões, foi deixada para depois pelo MEC. ${ }^{11}$

\footnotetext{
10 A última rodada do Pronex, já no governo atual (2003-06), foi marcada por uma grande polêmica entre a distribuição regional dos recursos e o sistema de mérito. O MCT privilegiou a sua interpretação de basear a distribuição por critérios regionais, sem — na opinião de seus dirigentes — descuidar-se da avaliação de mérito.

${ }^{11} \mathrm{O}$ novo governo divulga que fará, finalmente, uma reforma universitária.
} 
As tentativas de reordenação do setor de C\&T voltariam após a aprovação do Plano Diretor para a Reforma do Aparelho do Estado (Mare, 1995). O Plano Diretor mencionava, explicitamente, a atribuição para as universidades e os centros de pes-

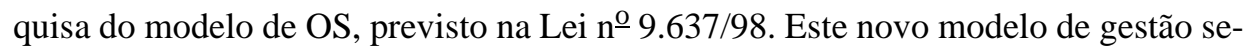
ria a conversão das entidades estatais em associações civis sem fins lucrativos, qualificadas por meio de decreto presidencial como organizações sociais. Esta qualificação daria prerrogativas especiais para estas associações civis como a competência para gerir verbas e patrimônio públicos e o poder de utilizar servidores públicos transferidos para os seus quadros (Mare, 1997).

A oposição ao modelo de organizações sociais foi grande no âmbito das universidades federais. Tanto o MEC, quanto a Associação Nacional de Dirigentes de Instituições Federais de Ensino Superior (Andifes), órgão que reúne os dirigentes das universidades e instituições isoladas federais, se posicionaram contra o modelo. A conclusão de ambos, no ano de 1998, foi pela necessidade de esperar que um projeto de autonomia universitária viesse atribuir um modelo condizente com as peculiaridades das universidades federais (Bresser-Pereira, 1998).

O modelo só teve efetivação maior no âmbito de algumas unidades de pesquisa do CNPq e do MCT. ${ }^{12}$ O Laboratório Nacional de Luz Síncrotron (LNLS) foi qualificado como organização social logo na edição da primeira medida provisória que criou o modelo em 1996 (Burgos, 1999). Depois foram qualificados como organizações sociais: o Instituto de Desenvolvimento Sustentável Mamirauá (IDSM), o Instituto Nacional de Matemática Pura e Aplicada (Impa) e a Rede Nacional de Pesquisa (RNP). Em 2002, diversas unidades de pesquisa consideravam a possibilidade de se converterem em organizações sociais, como o Laboratório Nacional de Computação Científica (LNCC) e o Laboratório Nacional de Astrofísica (LNA), entre outras. Como isto foi possível?

Antes de explicarmos como foi possível convencer os servidores e os dirigentes das unidades de pesquisa do MCT sobre a possibilidade de converter tais unidades em organizações sociais, cabe entender que houve uma linha de continuidade na política do MCT ao longo dos dois governos do presidente Fernando Henrique Cardoso (1995-2002). Esta linha teve duas vertentes. A primeira foi o ataque sistemático à burocracia das instituições estatais. E a segunda, a indução à aceitação das políticas governamentais sob a forma de prêmios.

\footnotetext{
${ }^{12}$ A exceção é a Associação de Comunicação Educativa Roquette Pinto, que absorveu as atividades da extinta Fundação Roquette Pinto, emissora da tradicional TV Educativa do Rio de Janeiro. Ela foi qualificada como organização social, quando da aprovação da medida provisória, junto com o LNLS.
} 
Em relação à primeira vertente podemos concluir que, para o MCT, todas as instituições estatais federais (universidades e unidades de pesquisa), em princípio, estariam operando com uma eficiência inferior ao seu potencial. Para liberar tal potencial seria necessário exterminar um “modelo arcaico de gestão” e, depois, ativar um novo modelo, mais dinâmico. Isso já podia ser visto identificado no discurso de José Galizia Tundisi, presidente do CNPq em 1995/96, na solenidade do aniversário de 45 anos do CNPq:

Precisamos é de mais eficiência e menos burocracia. Mais criatividade e menos burocracia. Mais organização científica e menos burocracia. O sistema de C\&T deve ser administrado com princípios científicos e conceituais e não com burocracia (...) O treinamento contínuo dos técnicos do CNPq é indispensável para eliminar, definitivamente, os vestígios de burocracia.

(SBPC, 1996:1)

Em 2001, um relatório de avaliação acerca das unidades de pesquisa do MCT (Brasil, 2001:47) chegou a conclusões semelhantes. Dizia que:

\begin{abstract}
Há uma necessidade urgente de se procurar uma mudança organizacional e de reforma do Estado, na área de ciência e tecnologia, para as instituições federais, em geral, e para as UPs [unidades de pesquisa] do MCT, em particular. Há que se vencer o modelo arcaico burocrático ainda vigente, que leva à perda dos muitos graus de liberdade para a gestão dos meios essenciais ao cumprimento da missão institucional, onde a administração indireta assume as terríveis características burocráticas da administração direta.
\end{abstract}

A segunda vertente, indução por premiação, estava presente desde a proposta de Laboratórios Associados ou Programa Nacional de Centros de Excelência (Pronex). Com ela, o ministério pretendia convencer os dirigentes e servidores de que se eles seguissem a política traçada pelo MCT seriam premiados. Para que o prêmio fizesse sentido, deveria haver uma pequena dose de punição para os mal avaliados, também. No cômputo final de premiações e punições, haveria um aumento da concorrência por verbas entre as unidades e isto seria saudável.

Podemos visualizar a segunda vertente em declarações públicas como a do ex-secretário executivo do MCT, Carlos Américo Pacheco, sobre a conversão de unidades de pesquisa em organizações sociais:

O ministério, demonstrando que pretende manter a excelência deste instituto [Impa], o transformou numa organização social. Só temos transformado insti- 
tutos em organizações sociais como prêmio à excelência, porque só as instituições extraordinariamente boas é que merecem, na verdade, a flexibilidade e um contrato de gestão na forma de Organização Social.

(Brasil, Câmara dos Deputados, 2001:30)

E vemos, pela declaração de um diretor de uma das unidades de pesquisa do MCT em 2001, inicialmente renitente à proposta de organizações sociais, que houve um paulatino convencimento sobre a aceitação do modelo:

A organização social está prevista dentro do esquema de governo. Então, é uma das opções (...). Na realidade, agora, as organizações sociais são uma forma de organização, mas elas podem ser financiadas pelo governo (...). Mas, tendo um bom contrato [de gestão] (com cláusulas de salvaguarda) pode ser um avanço, sobretudo do ponto de vista da gestão. Você pode passar a ter uma gestão mais empresarial; não fica com as amarrações das Leis de Licitações e [das] Contratações; você flexibiliza. Sobretudo na área de pesquisa que é uma área que tem que ser flexível. Então isso pode ser uma solução desejável.

Concluindo, o mesmo diretor, considerando a possibilidade de se transformar sua unidade de pesquisa em uma organização social, disse:

Acho que a gente não deve ter medo da organização social. Realmente é uma forma bem bolada que está sendo pensada aí. Que traz vantagens. De repente, traz até um orçamento maior, porque é um prêmio. De repente, eu até arriscaria.

A singularidade da questão estava colocada na seguinte proposição: será que ao converter-se algumas instituições, organizadas de modo estatal, em instituições geridas de forma privada se conseguirá libertá-las do jugo da burocratização? E mais: é desejável que a questão seja colocada neste prisma de prêmios e punições? Esta será nossa discussão a seguir.

\section{Conclusão: burocracia e burocratização}

Inicialmente, podemos mencionar que a burocracia e a burocratização configuram dois conceitos diferentes. Mais importante do que entender conceitualmente esta diferença é perceber que elas configuram dois objetos de análise distintos, apesar de relacionados. ${ }^{13} \mathrm{O}$ primeiro conceito, a burocracia, define estruturas sociais que podem ser públicas, privadas, estatais ou não. Usualmente, é um conceito que se desdo- 
bra em uma tipologia para mensuração do grau de complexificação das organizações. ${ }^{14}$ Já o segundo define um processo social em marcha nas complexas sociedades ocidentais. Assim, cabe mencionar que é importante visualizarmos as burocracias - e as suas histórias institucionais — como um modo de compreender, empiricamente, a burocratização social.

O processo de burocratização ocorre nas sociedades ocidentais por sua complexificação. É uma resposta racional ao aumento da complexidade da vida social. Não é somente uma característica do setor público e estatal como o senso comum tende a entender. Decorre da necessidade de organização de processos de produção complexos. Desse modo, as instituições produtivas também tendem a se burocratizar com a construção de mecanismos de controle e de gestão, procurando, assim, a garantia de eficiência. Entretanto, existe um desvio analítico do senso comum que, ao mesmo passo que enxerga o Estado como a solução dos grandes problemas nacionais (na formulação), considera que a sua execução fica:

[N]o âmbito da burocracia estatal, que, na percepção comum, é o reino da rotina, do formalismo, da incompetência e do parasitismo. Assim, a ficção comum legitimaria as qualidades da instituição formuladora e transferiria o ônus do fracasso para uma máquina desqualificada, anônima e, no final de contas, nãoresponsável.

(Alveal, 1994:111)

Preterindo a conceituação científica em prol de leituras próximas ao senso comum, acaba se negligenciando que o processo de burocratização das sociedades é mais profundo e deve ser solucionado não só com a mudança do Estado. Mas buscando a alteração nas relações sociais entre os campos do Estado, da sociedade civil organizada e das forças produtivas.

A intenção do MCT é racionalizar os investimentos para o setor. Ou seja, o ministério procura combater o desperdício de recursos e concentrar objetivos claros para as suas unidades de pesquisa. Com a focalização de objetivos, as suas unidades, apesar de pouco expressivas quantitativamente, ${ }^{15}$ fariam uma grande diferença qualitativa.

\footnotetext{
13 Um exemplo de síntese teórica sobre o tema está em Beetham (1996).

${ }^{14}$ Nas suas origens, designaria, também, um grau de racionalização destas estruturas sociais. Entretanto foi levantada grande quantidade de críticas acerca deste pressuposto. Principalmente, comprovando, a partir de estudos empíricos, que a burocratização não se traduzia, necessariamente, em racionalidade e eficiência (Coelho, 1976; e mais recentemente Friedberg, 1999).
} 
O problema está colocado no seguinte dilema: será que é possível acabar com a burocratização do setor de C\&T apenas com a extinção de algumas burocracias? Na verdade, isto não seria tentar terminar com o sintoma em vez da doença? As burocracias são erguidas ao longo de um processo de burocratização da vida social. Com a complexificação dos diversos setores, é necessário que se estabilizem e garantam as relações por meio de normas, regulamentos e procedimentos. Esse fenômeno foi antevisto por Weber (1999) como a criação e expansão da “jaula de ferro”. Quando o ministério procura induzir racionalidade por meio da desregulamentação de algumas unidades, não necessariamente resolve o problema da burocratização do setor de C\&T. Um singular exemplo desse afogamento em normas e regulamentos é a análise feita por Nunes (2002) do setor educacional e da sua extensa e confusa regulamentação que atinge, principalmente, as instituições de educação superior privadas.

As instituições que poderiam ser transformadas em organizações sociais representam uma parcela muito pouco expressiva, quantitativamente, do setor de C\&T. As unidades da CNEN, por exemplo, não podem ser convertidas em OS porque desenvolvem atividades estratégicas, protegidas constitucionalmente. O modelo de organizações sociais pode ser uma solução para instituições que precisem das verbas que seriam garantidas por este prêmio. Mas o modelo, infelizmente, não é uma solução para o funcionamento de todo o sistema de C\&T. Não é necessário descartar o modelo, como opção, mas é necessário ter claro que ele não será uma solução aplicável para todas as unidades de pesquisa federais.

O que cremos é que o setor de C\&T precisa ser revisto não somente do ponto de vista da gestão das suas organizações, mas, principalmente, pelo âmbito da relação entre as diversas instituições que o compõem. E, nessa revisão de relacionamento, devem estar incluídas não só as empresas. Também devem ser agregadas as universidades privadas, tradicionalmente relegadas a papéis secundários. E, ainda, a administração central, representada pelas financiadoras federais (CNPq, Capes e Finep) e os órgãos de planejamento de C\&T. Por fim, acreditamos que a aplicação do modelo de organizações sociais de modo generalizado poderia significar o desmanche de algumas instituições que não teriam capacidade para absorver tal transição.

\section{Referências bibliográficas}

\footnotetext{
15 Segundo a declaração de Carlos Américo Pacheco: “Os institutos [unidades de pesquisa] do ministério respondem por $4 \%$ do conjunto de doutores das instituições de pesquisa, ou seja, a ciência brasileira não é produzida, básica e diretamente, pelos institutos vinculados ao Ministério da Ciência e Tecnologia, parcela muito pequena da capacidade de produção do país” (Brasil, Câmara dos Deputados, 2001:8).
} 
ALVEAL, Carmen. Os desbravadores: a Petrobras e a construção do Brasil industrial. Rio de Janeiro: Relume-Dumará/Anpocs, 1994.

ANDRADE, Ana Maria Ribeiro de. Físicos, mésons e política: a dinâmica da ciência na sociedade. São Paulo: Hucitec/CNPq-Mast, 1999.

BAUMANN, Renato (Org.). Brasil: uma década em transição. Rio de Janeiro: Campus, 1999.

BEETHAM, David. Bureaucracy. 2. ed. Minneapolis: University of Minnesota Press, 1996.

BRASIL. Câmara dos Deputados. Audiência pública: Comissão de Ciência e Tecnologia, Comunicação e Informática. Brasília: Câmara dos Deputados, 2001.

BRASIL. MARE (MINISTÉRIO DA ADMINISTRAÇÃO E REFORMA DO ESTADO). Plano Diretor para a Reforma do Aparelho do Estado. Brasília: Mare, 1995.

1997.

MARE. Organizações sociais. Cadernos MARE da Reforma do Estado, n. 2, Brasília,

MCT (MINISTÉRIO DA CIÊNCIA E TECNOLOGIA). Relatório da Comissão de Avaliação das Unidades de Pesquisa do MCT. Brasília: MCT, ago. 2001. (Relatório).

; ABC (ACADEMIA BRASILEIRA DE CIÊNCIAS). Ciência, tecnologia, inovação: desafio para a sociedade brasileira (Livro Verde). Brasília: MCT/ABC, jul. 2001.

BRESSER-PEREIRA, Luiz Carlos. Crise econômica e reforma do Estado no Brasil: para uma nova interpretação da América Latina. São Paulo: Editora 34, 1996.

Reforma do Estado para a cidadania: a reforma gerencial brasileira na perspectiva internacional. São Paulo: Editora 34, 1998.

A reforma gerencial do Estado de 1995. Revista de Administração Pública. Rio de Janeiro, v. 34, n. 4, jul./ago. 2000.

BURGOS, Marcelo. Ciência na periferia: a luz síncrotron brasileira. Juiz de Fora: UFJF, 1999.

CASTRO, Maria Helena Guimarães de. Avaliação do sistema educacional brasileiro: tendências e perspectivas. Brasília: Inep, 1998.

COELHO, Edmundo Campos (Org.). Sociologia da burocracia. Rio de Janeiro: Zahar, 1976.

DINIZ, Eli; AZEVEDO, Sérgio. Apresentação. In: Reforma do Estado e democracia no Brasil. Brasília: UnB/Enap, 1997.

FALCÃO, Joaquim; CUENCA, Carlos. Mudança social e reforma legal: estudos para uma nova legislação do terceiro setor. Brasília: Comunidade Solidária, 1999.

FERLIE, Ewan et al. A nova administração pública em ação. Brasília: UnB/Enap, 1999.

RAP Rio de Janeiro 40(1):107-25, Jan./Fev. 2006 
FRIEDBERG, Erhard. Organização. In: BOUDON, Raymond (Org.). Tratado de sociologia. Rio de Janeiro: Jorge Zahar Editor, 1999.

LOPES, José Leite. Ciência e liberdade: escritos sobre ciência e educação no Brasil. Rio de Janeiro: MCT-CBPF/UFRJ, 1998.

NEVES, Abílio Baeta. Uma trajetória de alto nível. Revista Ciência Hoje, São Paulo, v. 29, n. 173, 2001.

NUNES, Edson. Teias de relações ambíguas: regulação e ensino superior. Brasília: Inep, 2002.

SCHOTT, Thomas. Performance, specialization and international integration of science in Brazil: changes and comparisons with other Latin American countries and Israel. In: SCHWARTZMAN, Simon (Coord.). Science and technology in Brazil: a new policy for a global world. Rio de Janeiro: FGV, 1995.

SCHWARTZMAN, S. Ciência e tecnologia no Brasil: uma nova política para um mundo global. In:- (Coord.). Ciência e tecnologia no Brasil: política industrial, mercado de trabalho e instituições. Rio de Janeiro: FGV, 1995.

SPINK, Peter Kevin. Possibilidades técnicas e imperativos em 70 anos de reforma administrativa. In: BRESSER-PEREIRA, Luiz Carlos; SPINK, Peter (Orgs.). Reforma do Estado e administração pública gerencial. Rio de Janeiro: FGV, 1998.

SBPC (SOCIEDADE BRASILEIRA PARA O PROGRESSO DA CIÊNCIA). Jornal da Ciência Hoje, Rio de Janeiro, n. 340, 22 mar. 1996.

VELLOSO, Jacques; VELHO, Léa. Mestrandos e doutorandos no país: trajetórias de formação. Brasília: Capes, 2001.

WEBER, Max. Economia y sociedad. México, DF: Fondo de Cultura Económica, 1999. 